\title{
Biogeochemical thallium cycling in high productivity coastal ocean compartments
}

\author{
CORINNA ELENA MORI ${ }^{1}$, MELANIE BECK ${ }^{1}$, MAREN \\ STRIEBEL $^{1,2}$, JULIAN MERDER ${ }^{3}$, BERNHARD \\ SCHNETGER $^{1}$, KATHARINA PAHNKE ${ }^{1}$ AND HANS- \\ JÜRGEN BRUMSACK ${ }^{1}$
}

${ }^{1}$ Institute for Chemistry and Biology of the Marine Environment (ICBM), Carl von Ossietzky University of Oldenburg

${ }^{2}$ Helmholtz Institute for Functional Marine Biodiversity (HIFMB), University of Oldenburg

${ }^{3}$ Department of Global Ecology, Carnegie Institution for Science, Stanford

Presenting Author: corinna.mori@uol.de

Thallium (Tl) is classified as non-(bio)-essential, highly toxic element in the marine environment. Despite its involvement in bio-cycling processes, it is considered to behave conservatively in open ocean settings. Studies from the coastal ocean of the southern North Sea, however, documented non-conservative concentration anomalies in seasonal and tidal patterns [1]. Thallium fixation in the sub- to anoxic parts of redox stratified coastal sediments was suggested as a driver for non-conservative depletion. Long-term time series data at the ICBM pile station [2] has shown that the observed $\mathrm{Tl}$ phenomenon is a recurring event. An inter-annual comparison shows that, although the occurrence of non-conservative Tl-concentration anomalies is similar in timing and seem to coincide with times of intensive organic matter cycling (e.g., algae blooms), their magnitude varies between the years. The aim of this study was to identify the drivers responsible for non-conservative $\mathrm{Tl}$ anomalies. In a highly interdisciplinary mesocosm approach we investigated the biogeochemical cycling of $\mathrm{Tl}$ during a phytoplankton bloom [3]. The great advantage of this approach is that it allowed us to fully control the physical forcing and focus on the biogeochemical processes affecting $\mathrm{Tl}$ cycling in one enclosed water body. Our findings suggest that the observed negative $\mathrm{Tl}$ anomalies were induced by its immobilization by organic (algae-detritus, cell lysis derived ligands) and inorganic (aluminosilicates) carrier phases in the water column prior to its deposition and potential fixation in the adjacent reducing sediments.

[1] Böning et al. (2018), GCA 227, 143-155

[2] Grunwald et al. (2010), J.Sea.Res.64, 199-212

[3] Mori et al. (2021), MarChem 229, 103910 